\title{
Composição química e digestibilidade aparente da energia e nutrientes da farinha de resíduos da indústria de filetagem de tilápias, para a tilápia do Nilo (Oreochromis niloticus)
}

\author{
Apparent energy digestibility and meal nutrients from tilapia filleting industrial waste for the Nile \\ tilapia (Oreochromis Niloticus L.)
}

\author{
Wilson Rogério Boscolo ${ }^{*}$ Carmino HayashiI ${ }^{\mathrm{II}}$ Aldi Feiden ${ }^{\mathrm{I}}$ Fabio Meurer ${ }^{\mathrm{II}}$ \\ Arcangelo Augusto Signor ${ }^{I}$
}

\section{RESUMO}

O trabalho foi realizado com objetivo de determinar os coeficientes de digestibilidade aparente (CD) da matéria seca (MS), proteína bruta (PB), energia bruta (EB) e a disponibilidade dos aminoácidos (AA), fósforo $(P)$ e cálcio (Ca) da farinha de resíduos da indústria de filetagem de tilápias (FT) para a tilápia do Nilo. Foram utilizadas 60 tilápias com peso e comprimento médio de $80,69 \pm 15,97 \mathrm{~g}$ e $15,97 \pm 1,87 \mathrm{~cm}$, respectivamente. Os animais foram submetidos à metodologia de coleta de fezes por sedimentação em tanques afunilados. A MS, PB e EB da FT apresentaram CD de 83,55, 88,13 e $84,74 \%$, respectivamente. Apresentando valores de proteína $e$ energia digestíveis de 44,39\% e 3799,02Kcal de ED kg-1. A FT apresenta CDa médio dos AA de 91,60\% com CDas variando de $67,90 \%$ para a Fen até $100 \%$ para a Arg e a Cis. O CD do $P$ foi de 70,44\% apresentando 1,94\% de P disponível, o CDa do Ca da FT é de 51,10\% apresentando 4,02\% de Ca disponível. A FT é um alimento protéico com bons índices de disponibilidade aparente de seus nutrientes e pode ser utilizado na alimentação de tilápias com a aplicação destes índices visando formular rações de custo mínimo que atendam às exigências da espécie.

Palavras-chave: ácidos graxos, aminoácidos, avaliação de alimentos, digestibilidade, farinha de resíduos de tilápia e tilápias.

\section{ABSTRACT}

Coefficients of apparent digestibility (CD) of dry matter (DM), crude protein (CP), crude energy (CE) and the availability of amino-acids $(A A)$, phosphorus $(P)$ and calcium (Ca) of meals from tilapia filleting industrial waste (FT) for the Nile tilapia were determined. Sixty tilapias, mean weight and length $80.69 \pm 15.97 \mathrm{~g}$ and $15.97 \pm 1.87 \mathrm{~cm}$ respectively, underwent feces collection by sedimentation in cone-bottom tanks. DM, CP and BE of FT had a CD of 83.55; 88.13 and $84.74 \%$ respectively, with digestible protein and energy rates equivalent to $44.39 \%$ and $3799.02 \mathrm{Kcal}$ of ED kg- $\mathrm{FT}$ had average CD of AA of $91.60 \%$, with CD varying from $67.90 \%$ for Fen up to $100 \%$ for Arg and Cis. Whereas CD of $P$ was $70.44 \%$ with $1.94 \%$ of available P, CD of Ca of FT amounts to $51.10 \%$ with $4.02 \%$ of Ca available. FT is a protein feed with a good index of apparent availability of its nutrients and may be used in feed of tilapia. Above indexes will produce low cost feeds that also meet the requirements of the fish.

Key words: amino acids, evaluation of feed, digestibility, fat acids, meals from tilapia waste, tilapia.

\section{INTRODUÇÃO}

A farinha de peixe é uma das principais fontes de proteína utilizadas em rações para peixes. As farinhas oriundas da pesca marinha, como as produzidas no Chile e Peru são as de melhor qualidade. Um grande problema enfrentado atualmente é o aumento na demanda por farinha de peixe, devido ao crescimento da aqüicultura, causando uma menor disponibilidade de produto no mercado mundial e conseqüentemente o aumento do seu custo. Além disto, a excessiva exploração dos recursos oceânicos para produção de farinhas de peixe, pode contribuir para o colapso dos estoques pesqueiros mundiais (NAYLOR et al., 2000).

IUniversidade Estadual do Oeste do Paraná (UNIOESTE). Rua da Faculdade, 645, 85903-000, Toledo, PR, Brasil. E-mail: wrboscolo@unioeste.br.*Autor para correspondência.

IIUniversidade Estadual de Maringá (UEM), Maringá, PR, Brasil.

IIIUniversidade Federal do Vale do São Francisco (UNIVASF), Petrolina, PE, Brasil. 
A substituição da farinha de peixe de origem marinha por subprodutos de origem animal, em rações para peixes, é uma das formas para se reduzir o custo de produção de organismos aquáticos (MILLAMENA, 2002). Um dos fatores limitantes do uso de subprodutos de origem animal em rações é a deficiência em nutrientes essenciais como aminoácidos e também o seu alto teor de cinzas (BOSCOLO et al. 2004).

A produção de resíduos de frigoríficos processadores de peixe, principalmente da indústria de filetagem de tilápias representa, segundo BOSCOLO et al. (2001), entre 62,5 e 66,5\% da matéria prima, sendo fundamental o processamento destes resíduos para redução do impacto ambiental. Além disto, a transformação destes resíduos em farinha é uma ótima opção de renda para as indústrias, podendo aumentar sua lucratividade. Alguns trabalhos recentes desenvolvidos com resíduos de indústrias processadoras de pescado têm demonstrado que estes subprodutos podem ser utilizados na alimentação de peixes (EL-SAYED, 1998; EL-SAYED, 1999; KOTZAMIS et al., 2001; MURRAY et al., 2003).

O conhecimento da digestibilidade da energia e nutrientes dos alimentos permite a formulação das rações de custo mínimo que atendam às exigências nutricionais dos animais (SULLIVAN \& REIGH, 1995; MCGOOGAN \& REIGH, 1996). Estudos de digestibilidade são importantes para o desenvolvimento de rações para o uso na aqüicultura (JONES \& DE SILVA, 1997). A digestibilidade é um dos aspectos mais relevantes para avaliar a capacidade de uma determinada espécie em utilizar os nutrientes de um determinado alimento ou ração completa (HANLEY, 1987), além de ser um indicador potencial da energia e nutrientes disponíveis para o crescimento, mantença e reprodução do animal, bem como dos níveis de nutrientes indigestíveis para avaliação de resíduos aquaculturais (CHO, 1993).

O objetivo do presente experimento foi caracterizar bromatologicamente a farinha de resíduos da indústria de filetagem de tilápias e determinar os coeficientes de digestibilidade aparente da sua energia e nutrientes para a tilápia do Nilo.

\section{MATERIAL E MÉTODOS}

O presente experimento foi realizado no Laboratório de Aqüicultura da Universidade Estadual do Oeste do Paraná - Campus de Toledo. Foram utilizadas 60 tilápias com peso e comprimento médio de 80,69 $\pm 15,97 \mathrm{~g}$ e 15,97 $\pm 1,87 \mathrm{~cm}$, respectivamente. Os animais foram submetidos à metodologia de coleta de fezes por sedimentação em tanques afunilados. Para a coleta de fezes por sedimentação foram utilizados quatro tanques de coleta de forma afunilada, com capacidade para 90L, com copo coletor na sua parte inferior, onde ficaram depositadas as fezes. Cada tanque de coleta de 90L com 15 animais foi considerado como uma unidade experimental.

Todos os animais de cada unidade experimental foram alojados em tanques-rede circulares construídos de tela plástica com malha de $15 \mathrm{~mm}$, sendo estes alojados em caixas plásticas de 310L, onde permaneciam durante todo o período de adaptação e durante o dia para alimentação no período de coleta de fezes. Este procedimento foi realizado para facilitar o manejo e evitar o contato dos peixes com restos de ração e fezes que por ventura estivessem depositados no fundo do tanque.

Os animais foram submetidos a um período de adaptação de quinze dias às instalações e manejo antes do início do experimento e de mais sete dias a cada ração experimental. O período de coleta de fezes foi de cinco dias para cada ração, formando desta maneira uma amostra composta (fezes de cinco dias) para cada unidade experimental, as fezes coletas foram congeladas para posteriores análises.

O arraçoamento durante o período de adaptação e de coleta foi realizado à vontade, cinco vezes ao dia, duas no período da manhã e três à tarde. Durante o período de coleta, após 15 minutos da última refeição as gaiolas com os peixes foram transferidos para os tanques de coleta, manejo este para evitar o regurgitamento da ração. A água utilizada, clorada, foi neutralizada através de adição diária de tiossulfito de sódio antes do abastecimento dos tanques.

Foram determinados os coeficientes de digestibilidade aparente (CD) da matéria seca (MS), proteína bruta (PB), energia bruta (EB), disponibilidade de aminoácidos (AA), cálcio (Ca) e fósforo (P) da farinha de resíduos da indústria de filetagem de tilápias (FT). Para a determinação da CD desse alimento, foi utilizada uma ração-referência purificada segundo FURUYA et al. (2001) e BOSCOLO et al. (2002a) e duas rações-testes com a inclusão da FT (Tabela 1), onde uma das rações-teste foi elaborada sem fosfato bicálcico para a avaliação da disponibilidade de P e Ca da FT e outra ração-teste formulada para a avaliação da digestibilidade da EB, PB e disponibilidade de AA da FT. O alimento avaliado foi moído em moinho tipo faca com peneira de $0,5 \mathrm{~mm}$ e posteriormente, as raçõesteste e referência foram umedecidas com água a $50^{\circ} \mathrm{C}$, e posteriormente peletizadas em um moinho de carne manual.

Para a determinação dos coeficientes de digestibilidade aparente da energia e dos nutrientes 
Tabela 1 - Composição percentual das dietas referências e teste utilizadas para a determinação dos coeficientes de digestibilidade aparente de alimentos para a tilápia do Nilo.

\begin{tabular}{lccc}
\hline Alimentos & Ração referência & Ração teste 1 & Ração teste 2 \\
\hline Albumina & 32,00 & 25,60 & 25,60 \\
Gelatina & 7,70 & 6,16 & 6,16 \\
Antioxidante BHT & 0,02 & 0,02 & 3,02 \\
Amido de milho & 44,68 & 35,74 & 35,74 \\
a-Celulose & 5,00 & 5,00 & 5,00 \\
Fosfato bicálcico & 3,00 & 2,40 & 0,00 \\
Óleo de soja & 6,00 & 4,80 & 4,80 \\
Suplemento (min + vit) ${ }^{1}$ & 1,00 & 1,00 & 1,00 \\
Sal & 0,50 & 0,50 & 0,50 \\
Óxido crômico & 0,10 & 0,10 & 0,10 \\
Alimento teste & 0,00 & 18,67 & 21,07 \\
Total & 100,00 & 100,00 & 100,00 \\
\end{tabular}

${ }^{1}$ Níveis de garantia por quilograma do produto (Rovimix peixes): Vit. A, 500.000UI; Vit. D 3 , 200.000UI; Vit. E, 5.000mg; Vit. K3, 1.000mg; Vit. B1, 1.500mg; Vit. B2, 1.500mg; Vit. B6, 1.500mg; Vit. B12, 4.000mg; Ác. Fólico, 500mg; Pantotenato Ca, 4.000mg; Vit. C, 15.000mg; Biotina, 50mg; Inositol, 10.000; Nicotinamida, 7.000; Colina, 40.000mg; Co, 10mg; Cu, 500mg; Fe, 5.000mg; I, 50mg; Mn, 1500mg; Se, 10mg; Zn, 5.000mg.

para a tilápia do Nilo, foi utilizada a metodologia indireta, utilizando-se como indicador o óxido crômico $\left(\mathrm{Cr}_{2} \mathrm{O}_{3}\right)$ segundo NRC (1993) incorporado na proporção de 0,1\% da ração.

Para análise as fezes foram descongeladas, secas em estufa de circulação forçada à $55^{\circ} \mathrm{C}$ por 24 horas, peneiradas para a retirada das escamas e moídas para a análise bromatológica, segundo metodologia descrita por SILVA (1990). Foram analisados também as rações e o alimento avaliado. As determinações da concentração de cromo nas fezes e nas rações-testes foram realizadas por espectrofotometria de absorção atômica segundo KIMURA \& MILLER (1957), para posterior cálculo do coeficiente de digestibilidade. Foi determinado também o perfil de ácidos graxos totais da FT segundo BLIGH \& DYER (1959), e método 5509 da ISO (1978) e o perfil de aminoácidos da FT.

O cálculo dos CD da MS, PB, EB e disponibilidade de AA, Ca e P da FT foram realizados de acordo com as equações utilizadas por MUKHOPADHYAY \& RAY (1997) de acordo com NRC (1993):

As variáveis químicas da água $(\mathrm{pH}$, condutividade e oxigênio dissolvido) foram monitoradas a cada três dias às 7h30. A temperatura foi medida diariamente às 7h30min e 16h30min.

\section{RESULTADOS E DISCUSSÃO}

Os valores médios de temperatura, oxigênio dissolvido, $\mathrm{pH}$ e condutividade elétrica, da água dos aquários durante o período experimental foram de 26,03 $\pm 0,80^{\circ} \mathrm{C} ; 7,14 \pm 1,41 \mathrm{mg} \mathrm{L}^{-1} ; 6,44 \pm 0,57 ;$ e $112,35 \pm$ $55,60 \mu \mathrm{S} \mathrm{cm}^{-1}$, respectivamente. Estes valores estão dentro da faixa aceitável para a criação de peixes de clima tropical (BOYD, 1990).

Na tabela 2, estão apresentadas os valores médios de MS, PB, EB, EE, MM, Ca, P, aminoácidos e ácidos graxos da farinha de resíduos de filetagem de tilápias (FT). AFT apresentou 50,37\% de PB na matéria natural, este valor que a caracteriza como um alimento protéico, porém este teor de PB é inferior aos observados para farinhas de peixe avaliadas por NENGAS et al. (1995), HARDY (1996) e OLVERANOVEA et al. (1997) que observaram valores de 68,16, 71,00 e $64,31 \%$ de PB, respectivamente. Em trabalhos de PEZZATO et al. (1988), HARDY (1996) e SUGIURA et al. (2000) estão relatadas farinhas de peixe com teores de 48,13, 57,50 e 46,90\% de PB, respectivamente, valores estes próximos ao encontrado no presente trabalho. Analisando estes valores encontrados na literatura podemos classificar as farinhas em pelo menos duas classes, ou seja, farinhas de primeira qualidade com teores de PB acima de 60\%, que provavelmente são produzidas a partir de peixes inteiros e farinhas de segunda, onde são utilizados na sua fabricação, resíduos de indústrias processadoras de pescado, apresentando PB ao redor de $50 \%$.

Um dos fatores limitantes do uso de farinhas de peixe obtidas de resíduos da indústrialização de pescados é o seu alto teor de cinzas (MILLAMENA, 2002; BOSCOLO et al. 2004) que, quando incluída em altos níveis em rações, irá refletir em altos teores de $\mathrm{P}$, que é o principal agente eutrofizador do ambiente 
Tabela 2 - Valores médios da composição bromatológica da farinha de resíduos da indústria de filetagem de tilápias (matéria natural).

\begin{tabular}{|c|c|c|c|}
\hline Nutrientes & & \multicolumn{2}{|c|}{ (\%) } \\
\hline Matéria seca $^{1}$ & & \multicolumn{2}{|c|}{94,10} \\
\hline Proteína bruta $^{1}$ & & \multicolumn{2}{|c|}{50,37} \\
\hline Energia bruta $\left(\mathrm{kcal} \mathrm{kg}^{-1}\right)^{2}$ & & \multicolumn{2}{|c|}{4483,09} \\
\hline Extrato etéreo $^{1}$ & & \multicolumn{2}{|c|}{21,77} \\
\hline Matéria mineral $^{1}$ & & \multicolumn{2}{|c|}{18,75} \\
\hline Cálcio $^{3}$ & & \multicolumn{2}{|c|}{7,87} \\
\hline Fósforo ${ }^{3}$ & & \multicolumn{2}{|c|}{2,78} \\
\hline \multicolumn{4}{|l|}{ Aminoácidos ${ }^{4}$} \\
\hline Essenciais & $\%$ & Não essenciais & $\%$ \\
\hline Arg & 4,16 & Asp & 4,17 \\
\hline Fen & 1,93 & Glu & 6,74 \\
\hline His & 1,00 & Cis & 0,40 \\
\hline Ile & 1,81 & Gli & 6,59 \\
\hline Leu & 3,32 & Pro & 4,22 \\
\hline Lis & 3,09 & Ala & 4,22 \\
\hline Met & 1,15 & Ser & 2,08 \\
\hline Tre & 2,10 & Tir & 0,82 \\
\hline Trp & 0,33 & & \\
\hline Val & 2,21 & & \\
\hline Ácido graxo ${ }^{5}$ & $\%$ & Total de ácidos graxos & $\%$ \\
\hline 14:0 & 1,96 & AGPI & 18,38 \\
\hline $14: 1 \mathrm{n}-5$ & 0,14 & AGMI & 45,76 \\
\hline 16:0 & 22,59 & AGS & 34,54 \\
\hline $16: 1 \mathrm{n}-9$ & 0,58 & $n-6$ & 15,93 \\
\hline 16:1 n-7 & 4,44 & $n-3$ & 3,78 \\
\hline $16: 1 \mathrm{n}-5$ & 0,29 & AGPI/AGS & 0,53 \\
\hline $17: 0$ & 0,63 & $n-6 / n-3$ & 4,22 \\
\hline 18:0 & 8,22 & Lipídeos totais & 20,26 \\
\hline 18:1 n-7 & 0,67 & & \\
\hline 18:1 n-9 & 38,81 & & \\
\hline $18: 2 n-6$ & 12,34 & & \\
\hline 20:0 & 0,45 & & \\
\hline $18: 3$ n-6 & 0,31 & & \\
\hline 20:1 n-11 & 0,83 & & \\
\hline $18: 3$ n-3 & 2,34 & & \\
\hline 21:0 & 0,69 & & \\
\hline $20: 4 n-6$ & 1,32 & & \\
\hline $20: 5 n-3$ & 0,31 & & \\
\hline $22: 4 \mathrm{n}-6$ & 1,15 & & \\
\hline $22: 5 n-6$ & 0,81 & & \\
\hline $22: 5 n-3$ & 0,49 & & \\
\hline $22: 6 n-3$ & 0,64 & & \\
\hline
\end{tabular}

${ }^{1}$ Análises realizadas no Laboratório de Tecnologia do Pescado/UNIOESTE.

${ }^{2}$ Análise realizada no Laboratório de Alimentos LANA/DZO/UEM.

${ }^{3}$ Análises realizadas no Laboratório de Análises de Solos DAG/UEM.

${ }^{4}$ Análises realizadas no LABTEC (Mogiana Alimentos).

${ }^{5}$ Análises realizadas no Laboratório de Alimentos do Departamento de Química da Universidade Estadual de Maringá.

(HARDY, 1996; SUGIURA et al., 2000). Na FT foi observado 18,75\% de matéria mineral, teor próximo ao observado por PEZZATO et al. (1988), HARDY (1996) e ROSTAGNO et al. (2000) em farinhas de peixes produzidas a partir de resíduos de pescado. Valores superiores ao encontrado no presente experimento foram observados por BOSCOLO et al. (2004) que avaliando FT, os quais encontraram 30,13\% de cinzas e

Ciência Rural, v.38, n.9, dez, 2008. 
SUGIURA et al. (2000), avaliando uma farinha de peixe produzida com pele e ossos, que obtiveram $38,50 \%$ de cinzas. Por outro lado, as farinhas de melhor qualidade apresentam níveis de cinzas inferiores a 15\% de MM (GAYLORD \& GATLIN, 1996; MAINA et al., 2002; SALES \& BRITZ, 2003).

O teor de gordura da FT avaliada neste experimento foi de $21,77 \%$, valor este próximo ao observado por BOSCOLO et al. (2004) para a FT. Na maioria das farinhas de peixe comerciais, descritas por outros autores, a percentagem de gordura situa-se próximo de $10 \%$. Esta diferença entre o teor de gordura da FT com a maioria das farinhas de peixes comerciais se deve principalmente à sua constituição física, que é compreendida por uma grande parcela de vísceras que é o principal local de depósito de gordura das tilápias. A alta percentagem de gordura da FT poderia ser minimizada mediante uma prensagem mais drástica da matéria-prima durante o seu processamento, mas isto aumentaria o teor de minerais da FT podendo limitar a sua inclusão em rações.

A FT apresenta teor aminoacídico inferior ao apresentado por estas farinhas de primeira qualidade principalmente as originárias do Chile, Peru e Dinamarca, principalmente com relação aos AA essenciais. A FT apresenta cerca de $60 \%$ da quantidade de lisina destas farinhas. Com relação aos AA não essenciais, podemos observar que os teores de glutamato, glicina, prolina e alanina são semelhantes aos de LEE et al. (2002), ALLAN et al. (2000) e SALES \& BRITZ (2003).

Em peixes tropicais os ácidos graxos polinsaturados da série n-3 e n-6 são importantes nutricionalmente, o ácido linolênico 18:3 (n-3) e o ácido linoléico 18:2 (n-6) satisfazem as exigências de ácidos graxos essenciais das séries n-3 e n-6, respectivamente (BELL et al., 1986). As tilápias exigem 0,5\% do ácido graxo linoléico na sua dieta (NRC, 1993) e a FT apresenta 12,34\% deste ácido graxo, portanto, apenas 5\% de inclusão de FT em rações suprem as exigências para tilápias.

Os coeficientes e valores de disponibilidade e digestibilidade aparente da energia e nutrientes da FT para a tilápia do Nilo (Tabela 3). A FT apresentou CD da MS (83,55\%) superior aos obtidos por FURUYA et al. (2001) e PEZZATO et al. (2002), porém inferior aos apresentados por PEZZATO et al (1988) e MEURER et al (2003) todos estes também para a tilápia do Nilo.

Tabela 3 - Coeficientes e valores de disponibilidade e digestibilidade aparente da energia e nutrientes da farinha de resíduos da indústria de filetagem de tilápias para a tilápia do Nilo.

\begin{tabular}{|c|c|c|}
\hline Nutrientes & Coeficientes de digestibilidade (\%) & Nutrientes digestíveis (\%) \\
\hline Matéria seca & 83,55 & - \\
\hline Proteína & 88,13 & 44,39 \\
\hline \multirow[t]{2}{*}{ Energia (kcal kg ${ }^{-1}$ ) } & 84,74 & 3799,02 \\
\hline & Coeficientes de disponibilidade (\%) & Nutrientes disponíveis (\%) \\
\hline Fósforo & 70,44 & 1,94 \\
\hline Cálcio & 51,10 & 4,02 \\
\hline Aminoácidos & Coeficientes de disponibilidade (\%) & Nutrientes disponíveis (\%) \\
\hline Ala & 90,20 & 3,81 \\
\hline Arg & 104,36 & - \\
\hline Asp & 90,88 & 3,79 \\
\hline Glu & 97,53 & 6,57 \\
\hline Cis & 118,74 & - \\
\hline Fen & 67,90 & 1,31 \\
\hline Gli & 94,38 & 6,22 \\
\hline His & 89,99 & 0,90 \\
\hline Ile & 92,69 & 1,68 \\
\hline Leu & 98,05 & 3,25 \\
\hline Lis & 86,65 & 2,68 \\
\hline Met & 92,51 & 1,06 \\
\hline Pro & 95,14 & 4,01 \\
\hline Ser & 96,27 & 1,97 \\
\hline Tre & 74,53 & 1,56 \\
\hline Tir & 98,14 & 0,81 \\
\hline Trp & 97,84 & 0,33 \\
\hline Val & 86,13 & 1,90 \\
\hline
\end{tabular}


O CD da PB da FT (88,13\%) foi superior aos determinados por FURUYA et al. (2001), BOSCOLO et al. (2004) e PEZZATO et al. (2002) avaliando farinhas obtidas de indústrias processadoras de pescado. Comparando o CDa da PB da FT com os resultados obtidos com farinhas fabricadas com peixes inteiros avaliadas por HANLEY (1987) e DEGANI et al. (1997) observamos que os CDas são bastante próximos, indicando que a fração protéica da FT é bem digerida e absorvida pela tilápia do Nilo. Por outro lado, os dados do presente experimento foram inferiores dos de PEZZATO et al. (1988). No trabalho de BOSCOLO et al. (2004) o baixo CDa da PB observado pelos autores (67,09\%) pode ter sido devido ao alto nível de MM da farinha avaliada (30,13\%), pois segundo SUGIURA et al. (2000), quanto maior a quantidade de cinzas da farinha de peixe menor será o $C D$ da $\mathrm{PB}$.

A energia de um alimento é derivada de seus nutrientes, principalmente dos lipídeos, proteínas e carboidratos, sendo o CD da EB do alimento dependente da habilidade dos peixes em digerir e absorver estes nutrientes (NRC, 1993). A tilápia do Nilo é um peixe onívoro que potencialmente é capaz de utilizar estes nutrientes de diversos alimentos convencionais e alternativos como fonte de energia (FURUYA et al., 2001; BOSCOLO et al., 2002ab, PEZZATO et al., 2002; MEURER et al., 2003). Na FT o CD da EB foi de 84,74\% apresentando 3799,02Kcal de energia digestível por quilo do ingrediente.

O valor biológico da proteína de um alimento é dependente da sua digestibilidade, balanço e disponibilidade dos AA. Segundo SALES \& BRITZ (2003) os valores de disponibilidade aparente de AA, estão bastante próximos dos verdadeiros e estes dados podem ser utilizados para obter uma formulação de ração mais precisa (MASSUMOTO et al., 1996). AFT apresenta CD médio dos AA de 91,60\%, valor este ligeiramente superior ao seu CD da PB (88,13\%), e isto pode ser devido à fração de nitrogênio não protéico do alimento. No entanto, deve-se dar preferência aos valores de AA disponíveis, pois processamentos com superaquecimento podem reduzir a disponibilidade de aminoácidos como a lisina, metionina e histidina (MASUMOTO et al., 1996). Este CD médio é considerado muito bom, pois apresenta-se semelhante aos encontrados na literatura para farinhas importadas do Peru e Chile, as quais são consideradas as melhores do mundo.

Os CD dos AA arginina e cistina da FT foram de 104,36 e $118,74 \%$, respectivamente, valores que podem estar relacionados ao fato de que, nas fezes da ração teste com a inclusão da FT não foram encontrados vestígios destes AA. Portanto, a disponibilidade destes AA deve ser considerada 100\%. Este fato também foi observado por MASUMOTO et al. (1996) para o coeficiente de digestibilidade verdadeiro de vários aminoácidos da caseína. Os CDa dos outros AA são semelhantes aos observados por MASUMOTO et al. (1996), ALLAN et al. (2000), FURUYA et al. (2001) e SALES \& BRITZ (2003), para a farinha de peixe tipo "Menhaden meal”, farinha de peixe marrom Chilena, farinha de peixe Peruana, resíduos de processamento de pescado e farinha de origem Dinamarquesa, respectivamente.

Com a intensificação da piscicultura aumenta também a preocupação com os resíduos produzidos nesta atividade. O P é considerado como o principal agente eutrofizador do ambiente (HARDY, 1996; SUGIURA et al., 2000), e, portanto, é de suma importância à formulação de rações com alimentos com alta disponibilidade deste nutriente, visando minimizar o impacto tanto para a própria criação como ambiental. A FT avaliada neste estudo apresentou alto CD do P (70,44\%) com 1,94\% de P disponível, a FT é, portanto um ingrediente com alto potencial para ser incluído em rações para a tilápia do Nilo. O Ca é um macronutriente importante, pois é responsável pela rigidez dos ossos, além de outras importantes funções metabólicas e seu CD é de 51,10\% apresentando 4,02\% de cálcio disponível.

Com relação ao Ca a FT apresentou CDa entre os valores de CDas encontrados na literatura para diversas farinhas de peixe, variando de $11,80 \% 59,56 \%$ (RICHE \& BROWN, 1996; GAYLORD e GATTLIN, 1996; NORDRUM et al., 1997; SUGIURA et al., 2000 e FURUYA, 2000). Estes valores são ainda mais discrepantes que os observados para o $\mathrm{P}$, variando de $-0,10$ a 94,09\%. Esta variação pode ser devido à metodologia empregada, espécie em função de diferenças na fisiologia da digestão, qualidade da matéria-prima ou tamanho da partícula do ingrediente (SUGIURA et al., 2000).

\section{CONCLUSÃO}

A farinha de resíduos da indústria de filetagem de tilápias é um alimento protéico com bons índices de disponibilidade aparente de seus nutrientes e pode ser utilizado na alimentação da tilápia do Nilo, com a aplicação dos valores de digestibilidade dos nutrientes, visando formular rações de custo mínimo que atendam às exigências da espécie.

\section{REFERÊNCIAS}

ALLAN,G.L. et al. Replacement of fish meal in diets for Australian silver perch, Bidyanus bydyanus: I. Digestibility of alternative ingredients. Aquaculture, v.186, p.293-310, 2000. 
BELL, M.V. et al. The role of polyunsaturated fatty acids in fish. Comparative biochemistry and physiology, v.83B, p.711-719, 1986.

BLING, E.G.; DYER, W.J. A rapid method of total lipid extraction and purification. Canadian Journal of Biochemistry and Physiology, v.37, n.8, p.911-917, 1959.

BOSCOLO, W.R. et al. Digestibilidade aparente da energia e proteína das farinhas de resíduo da filetagem da tilápia do Nilo (Oreochromis niloticus), da corvina (Plagioscion squamosissimus) e farinha integral do camarão canela (Macrobrachium amazonicum) para a tilápia do Nilo. Revista Brasileira de Zootecnia, v.33, n.1, p.8-13, 2004.

BOSCOLO, W.R. et al. Digestibilidade aparente da energia e nutrientes de alimentos convencionais e alternativos para a Tilápia do Nilo (Oreochromis niloticus, L.). Revista Brasileira de Zootecnia, v.13, n.2, p.539-545, 2002a.

BOSCOLO, W.R. et al. Farinha de varredura de mandioca (Manihot esculenta) na alimentação de alevinos de Tilápia do Nilo (Oreochromis niloticus L.). Revista Brasileira de Zootecnia, v.13, n.2, p.545-551, 2002b.

BOSCOLO, W.R. Desempenho e características de carcaça de machos revertidos de tilápias do Nilo (Oreochromis niloticus), linhagens tailandesa e comum, nas fases iniciais e de crescimento. Revista Brasileira de Zootecnia, v.30, n.5, p.1391-1396, 2001

BOYD, C. Water quality in ponds for aquaculture. London: Birmingham Publishing, 1990. 482p.

CHO, C.Y. Digestibility of feedstuffs as a major factor in aquaculture waste management. In: KAUSHIK S.J.; LAQUET, P. (Ed.). Fish nutrition in practice. Biarritz, France: INRA, 1993. 374p.

DEGANI, G. et al. Apparent digetibility of protein and carbohydrate in feed ingredients for adult tilapia (Oreochromis aureus $\mathrm{X} O$. niloticus). Israeli Journal of aquaculture, v.49, n.3, p.117-123.

FURUYA, W.M. Digestibilidade aparente de aminoácidos e substituição da proteína da farinha de peixe pela proteína do farelo de soja com base no conceito de proteína ideal em rações para a tilápia do Nilo (Oreochromis niloticus 1.). 2000. 69f. Tese (Doutorado em Zootecnia) - Universidade Estadual Paulista, Botucatu, SP.

FURUYA, W.M. et al. Coeficientes de digestibilidade e valores de aminoácidos digestíveis de alguns ingredientes para Tilápia (Oreochromis niloticus). Revista Brasileira de Zootecnia, v.30, p.1143-1149, 2001.

GAYLORD, T.G.; GATLIN III, D.M. Determination of various feedstuffs for red drum (Sciaenops ocellatus). Aquaculture, v.139, p.303-314, 1996

HANLEY, F. The digestibility of foodstuffs and the effects of feeding selectivity determinations in tilápia, (Oreochromis niloticus L). Aquaculture. v.66, n.2, p.163-179, 1987.

HARDY, R.W. Alternate protein sources for salmon and trout diets. Animal Feed Science Technology, v.59, p.71-80, 1996.
ISO INTERNATIONAL ORGANIZATION FOR STANDARDIZATION. Animal and vegetable fats and oils preparation of methyl esters of fatty acids. Geneve, 1978. ISSO 5509, p. 01-06.

JONES, P.L.; DE SILVA, S.S. Apparent nutrient digestibility of formuled diets by the Australian freshwater crayfish Cherax destructor Clark (Decapoda, Parastacidae). Aquaculture Research, v.28, n.11, p.881-891, 1997.

KIMURA, F.T.; MILLER, V.L. Improved determination of chromic oxide in cal feed and feces. Journal Agriculture Food Chemistry, v.5, n.2, p. 216, 1957.

KOTZAMIS,Y.P. et al. Utilization of waste material resulting from trout processing in gilthead brean (Sparus aurata L.) diets. Aquaculture Research, v.32, suppl.1, p.288-295, 2001.

LEE, S.M. Apparent digestibility coefficients of various feed ingredients for juvenile and grower rockfish (Sebastes schlegeli). Aquaculture, v. 207, p.79-95, 2002.

MAINA, J.G. et al. Digestibility and feeding value of some feed ingredients fed to tilapia Oreochromis niloticus (L.). Aquaculture Research, v.33, p.853-862, 2002.

MASUMOTO, T. et al. Amino acid availability values for several protein souces for yellowtail (Seriola quinqueradiata). Aquaculture, v.146, p.109-119, 1996.

MCGOOGAN, B.B.; REIGH, R.C. Apparent digestibility of selected ingredients in red drum (Sciaenops ocellatus) diets. Aquaculture, v.14, p.233-244, 1996.

MEURER, F. et al. Digestibilidade aparente dos nutrientes e energia de alguns alimentos protéicos para juvenis de tilápia do Nilo (Oreochromis niloticus). Revista Brasileira de Zootecnia, v.32, n.6, p.1801-1809, 2003.

MILLAMENA, O.M. Replacement of fish meal by animal byproduct meals in a practical diet for grow-out culture of grouper Epinephelus coiodes. Aquaculture, v.204, p.75-84, 2002.

MUKHOPADHYAY, N.; RAY, A.K. The apparent total and nutrient digestibility of sal seed (Shorea robusta) meal in rohu, Labeo rohita (Hamilton), fingerlings. Aquaculture Research, v.28, p.683-689, 1997.

MURRAY, A.L. et al. Effects of various feed supplements containing fish protein hydrolysate or fish processing byproducts on the innate immune functions of juvenile coho salmon (Oncorhynchus Kisutch). Aquaculture, v.220, p.643653, 2003.

NATIONAL RESEARCH COUNCIL - NRC. Nutrient requirements of warmwater, fishes and shellfishes: nutrient requirements of domestics animals. Washington, 1993. $114 \mathrm{p}$

NAYLOR, R.L. et al. Effect of aquaculture on world fish supplies. Nature, v.405, n.29, p.1017-1024, 2000.

NENGAS, I. et al. Investigation to determine digestibility coefficients of various raw materials in diets for gilthead sea 
bream, Sparus auratus L. Aquaculture Research, v.26, p.185-194, 1995.

NORDRUM, S. et al. Availability of phosphorus in fish bone meal and inorganic salts to atlantic salmon (Salmo salar) as determined by retention. Aquaculture, v.157, p.51-61, 1997.

OLVERA-NOVOA, M.A. et al. Cowpea (Vigna unguiculata) protein concentrate as replacement for fish meal in diets for tilapia (Oreochromis niloticus) fry. Aquaculture, v.158, p.107-116, 1997.

PEZZATO, L.E. et al. Digestibilidade Aparente de ingredientes, pela tilápia do Nilo (Oreochromis niloticus). Revista Brasileira de Zootecnia, v.31, p.1595-1604, 2002.

PEZZATO, L.E. et al. Digestibilidade aparente de fontes protéicas pela tilápia do Nilo (Oreochromis niloticus). In: SIMPÓSIO LATINOAMERICANO, 6.; SIMPÓSIO BRASILEIRO DE AQUICULTURA, 5., 1988, Florianópolis, SC. Anais... Florianópolis: SIMBRAC, 1988. p.373-378.
RICHE, M.; BROWN, P.B. Availability of phosphorus from feedstuffs fed to rainbow trout, Oncorhynchus mykiss. Aquaculture, v.142, p.269-282, 1996.

ROSTAGNO, H.S. et al. Tabelas brasileiras para aves e suínos. Viçosa: ed.UFV, 2000. 141p.

SALES, J.; BRITZ, P.J. Apparent and true availability of amino acids from common feed ingredients for South African abalone (Haliotis midae L.). Aquaculture Nutrition, v.9, p.55-64, 2003.

SILVA, D.J. Análise de alimentos (método químicos e biológicos). Viçosa: UFV, 1990. 165p.

SUGIURA, S.H. et al. Utilization of fish and animal by-product meals in low-pollution feeds for rainbow trout Oncorhynchus mykiss (Walbaum). Aquaculture Research, v.31, p.585-593, 2000 .

SULLIVAN, J.A.; REIGH, R.C. Apparent digestibility of selected feedstuffs in diets for hybrid striped bass (Morene saxatilis $\mathrm{x}$ Morene chrysops). Aquaculture, v.138, p.313-322, 1995. 